\title{
Complex ice stream flow revealed by sequential satellite imagery
}

\author{
Ted A. Scambos \\ Hughes STX Corporation, 4400 Forbes Boulevard, Lanham, MD 20706, U.S.A. \\ ROBERT BINDSCHADLER \\ Code 971, NASA/Goddard Space Flight Center, Greenbelt, MD 20771, U.S.A.
}

\begin{abstract}
The velocity field of the confluence area of two large ice stream tributaries forming Ice Stream D in West Antarctica is studied using sequential Landsat images. Sequential satellite image analysis allows for a very high density of velocity measurements, based on computer-measured displacements of features such as crevasses, crevasse scars, and ice mounds recognizable in both images. Automated displacement measurement of these features results in a detailed map of surface velocities from which surface-horizontal strain-rate fields can be calculated. Correlations between the surface morphology, the velocity field, and the strainrate field of Ice Stream D reveal a number of important characteristics of ice stream flow:

- the characteristic flowband appearance of streaming ice is present at velocities from below $100 \mathrm{~m} \mathrm{a}^{-1}$ to above $350 \mathrm{~m} \mathrm{a}^{-1}$;

- in the upstream areas, there appears to be no sharp transition between "sheet" flow, typical of the surrounding ice sheet, and "streaming" flow;

- the fastest moving portions of the ice stream are nearly devoid of surface topography undulations;

- the confluence area is characterized by acceleration of the ice in the slower tributary as it impinges on faster-moving ice, and by highly convergent flow. Velocity in the faster-moving tributary changes little, and there is no persistent evidence of the shear margins of the joined tributaries downstream of the confluence.
\end{abstract}

This study demonstrates that sequential satellite image analysis, coupled with computer-determined displacement measurements, can provide accurate velocity and strain-rate information on a regional scale rapidly and cost-effectively. Such data sets are required for modelling ice sheet evolution, and for monitoring any changes in ice flow within the ice streams.

\section{INTRODUCTION}

The recent application of computer image-matching algorithms to sequential satellite imagery of ice stream areas (Bindschadler and Scambos, 1991; Scambos and others, 1992) has greatly increased the ability to determine the large-scale velocity field of ice streams. With this technique, analysis of large areas of the ice sheets may be done rapidly and at low cost relative to field methods; however, the technique is limited to those regions accessible by high-resolution imaging satellites (equator-ward of $84^{\circ} \mathrm{N}$ or $\mathrm{S}$ for SPOT, or $82.5^{\circ}$ for Landsat TM). To date, our reports on the use of this method have discussed the first-order observations that may be made from the velocity field alone. However, by applying our method to both coregistration of the images and dense measurement of the surficial ice velocity (see Scambos and others, 1992), it is possible to determine the velocity field well enough to calculate accurate strain-rate

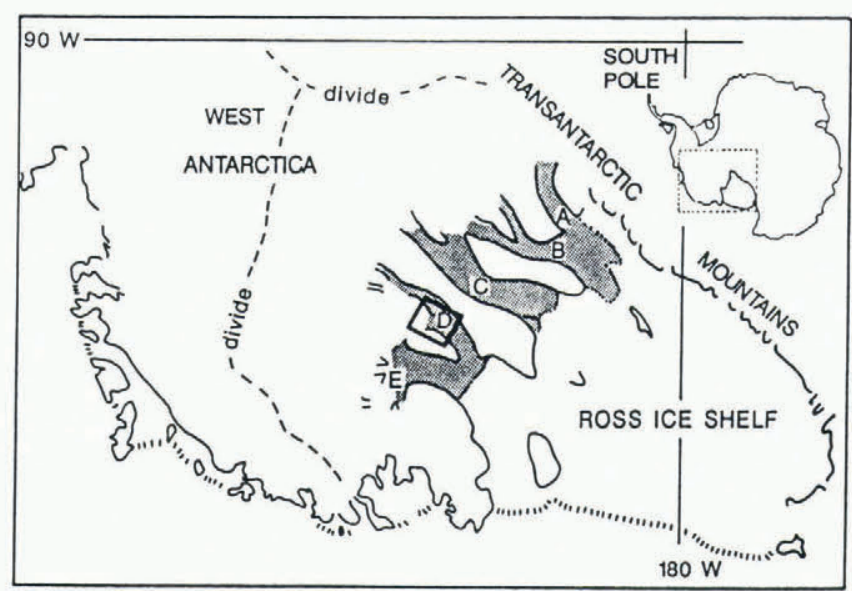

Fig. 1. Location of the study area. 
fields as well. Thus, sequential satellite imagery can be used to study ice kinematics in detail, without the requirement of a field party, and over areas larger than are easily handled with field techniques. This technique is particularly well suited to studying complex ice flow areas because these areas are generally densely crevassed. Smooth, featureless areas are not easily measured from the imagery, but are more likely to be visited by field parties, making these two methods complimentary.

The study area is an upstream portion of Ice Stream D in the Siple Coast region of West Antarctica (Fig. 1). Previously, the method has been applied to a region of generally parallel flow on Ice Stream E (Bindschadler and Scambos, 1991; Scambos and others, 1992). This study covers a more complex area, centered on the convergence of two tributaries which form the main trunk of Ice Stream D (Fig. 2a). The characterization of these types of areas, and the quantification of ice stream velocity fields on a regional basis, is critical if accurate time-dependent models of ice stream flow are to be developed.

\section{DATA ACQUISITION TECHNIQUE}

The technique used here to measure surface velocity is discussed in detail in Scambos and others, 1992. Displacement measurements of small surface features on the ice are made using an image cross-correlation algorithm on small image "chips" from two co-registered satellite images separated in time by a few years. The brightness of pixels in the chips is compared on a pixel-bypixel basis as the chips are shifted over each other, and a correlation value is determined for every possible placement of one chip over the other. By interpolating the magnitude of the correlation values in the vicinity of the best integer pixel location matches, it is possible to determine the displacement of one chip to match the other chip to subpixel resolution. This approach improves upon techniques that attempt to pick specific pixels representing the same feature in two images. Careful preprocessing of the images maximizes the number and quality of displacement measurements. In the present study, using Landsat TM data, the first principal component $(\mathrm{PCl})$ of the raw image data from bands 2 , 3,4 , and 5 was used. This reduced noise and enhanced topographic features. Scan-line noise was removed from the PCl images using a filtering algorithm (Crippen, 1989), and sun-angle variation over the scenes was removed. Each image was then spatially filtered, separating surface features according to scale: low-pass filtered images contained features of greater than $700 \mathrm{~m}$; and high-pass filtered images contained features smaller than $700 \mathrm{~m}$. The low-pass filtered images, essentially images of the long-wavelength surface topography undulations, were used for coregistration. Long-wavelength undulations are directly related to the underlying bed topography (Budd and Carter, 1971), and are therefore fixed in position. The undulation fields were matched by eye to a level of \pm 1 pixel and a best-fit subpixel match of the fields was determined by examining $37512 \times 512$ pixel chip pairs in the two scenes. These were used to calculate subpixel corrections for residual mismatch over the image. In the present case, the corrections were on the order of 0.1 to 0.4 pixels over the scene (equivalent to 1.5 to $6 \mathrm{~m} \mathrm{a}^{-1}$ correction to velocities).

The high-pass filtered images are dominated by crevasses, crevasse scars, and large dunes; features that move with the surface velocity of the ice. The same imageto-image cross-correlation algorithm is applied to chips derived from the high-pass filtered images; however, when a match is found in this case, the difference between the coregistration vector and the vector required to match the smaller surficial features is interpreted to be the displacement of the ice over the time interval between the two images. Dividing by the time interval gives the velocity of the ice relative to the large-scale undulations.

The Landsat TM scenes used for this study are both of Path 7, Row 119 scene center (scenes 510511451 and 423411503 ) and were acquired on 16 January 1987 and 12 December 1988, a separation of nearly two years. After preprocessing and determination of the coregistration vector, displacement measurements were attempted on over 16500 chip pairs distributed over the study area (roughly one every $20 \times 20$ pixels). Chip size was $64 \times 64$ pixels, or $1800 \times 1800 \mathrm{~m}$ (one Landsat TM pixel represents $28.5 \times 28.5 \mathrm{~m}$ on the surface). 3522 matches that passed several quality criteria (correlation strength, estimated error of match location, handselecting to eliminate upstream or cross-stream matches) were found. The majority of failed attempts were in areas with no small surface features, i.e. in areas devoid of crevasses or other ice features, or in areas where high shear stresses have created chaotic crevasse patterns. In well-featured areas the success rate was $>80 \%$. Errors of the selected points are typically $<0.35$ pixels, and none is worse than \pm 1.5 pixels. Coupled with the time separation of nearly two years, the accuracy of individual velocity measurements is approximately $\pm 6 \mathrm{~m} \mathrm{a}^{-1}$. There may be an additional systematic error of up to $\pm 6 \mathrm{~m} \mathrm{a}^{-1}$ over the whole field based on the accuracy of the coregistration.

\section{VELOCITY AND STRAIN-RATE MAPS, AND ICE STREAM FEATURES}

Velocity data were interpolated to a grid with a spacing of 36 pixels $(\sim 1.0 \mathrm{~km})$ and speed values were contoured by computer (Fig. 2b). Since the grid spacing is coarser than the velocity data, in areas of dense data the precision of the speed contour map is better than the precision for a single measurement $\left( \pm \sim 6 \mathrm{ma}^{-1}\right.$ error $/ \sqrt{ } 3.24$ measurements/grid spac. $= \pm \sim 3.3 \mathrm{~m} \mathrm{a}^{-1}$ error for gridpoints). Strain-rate maps are shown in Figure 3a, b, and c. These are derived from the velocity grid using a centered difference scheme that calculates strain rate components relative to the grid axes, then transforms the components to longitudinal, transverse, and shear components in the local along-flow, across-flow coordinate system. The strain-rates calculated from the velocity grid are smoothed to a 60 -pixel $(1.7 \mathrm{~km})$ grid spacing. Errors for the gridded strain-rate measurements are approximately $\pm 0.0025 \mathrm{a}^{-1}$ in areas of dense velocity measurements.

Several first-order observations may be made by inspection of the velocity map and velocity profiles taken 

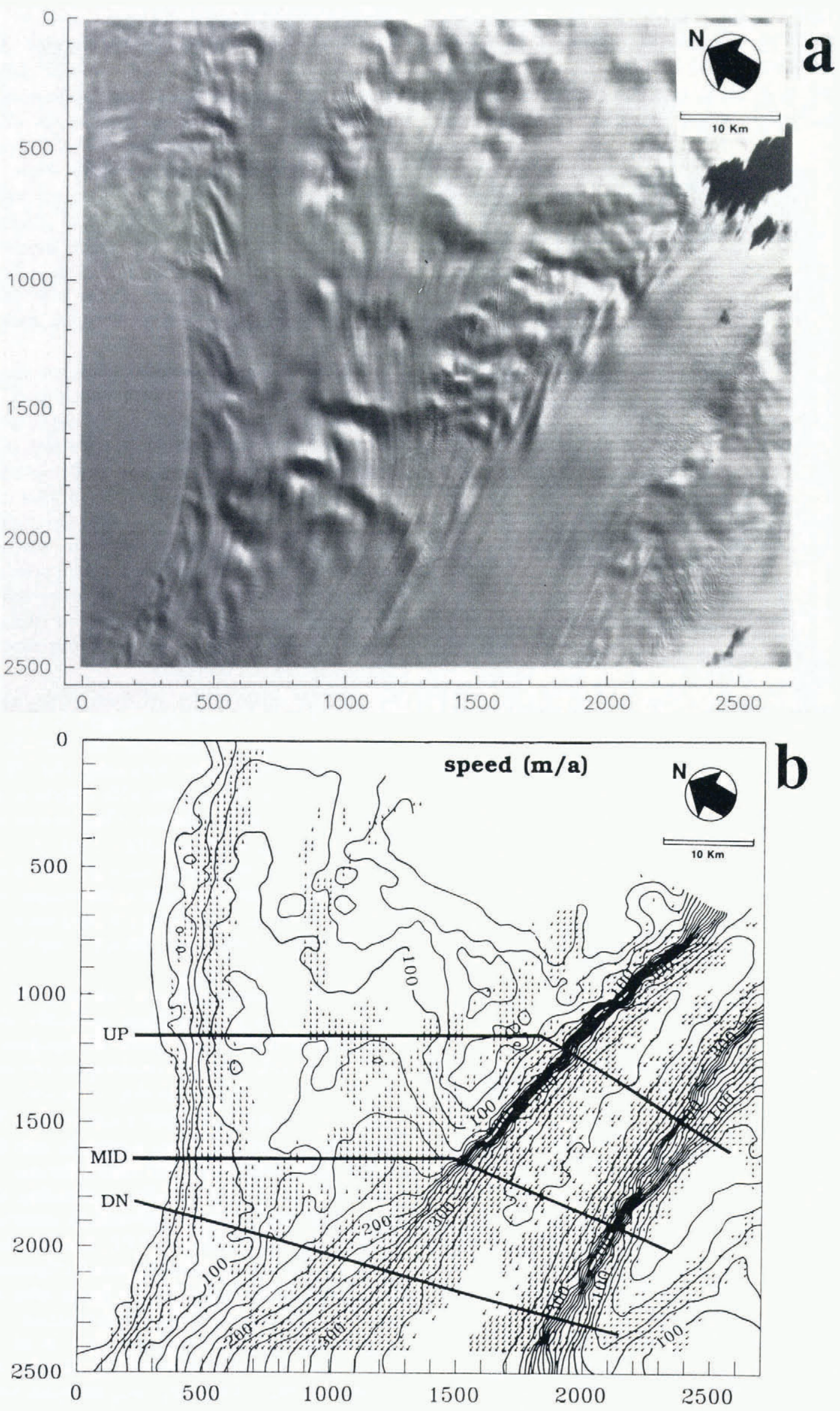

Fig. 2. (a) Landsat TM image of the upstream portion of Ice Stream D (16 January 1987 scene). Flow is from top to bottom of the image. Flowbands in the ice stream are parallel to flow direction throughout the scene. Axes are image coordinates for the study area in pixels. (b) Velocity field for the study area. Locations, flow directions, and magnitudes of the displacement measurements used for the mapping are shown as arrows that scale with speed. Countours are in $m a^{-1}$. Locations of the speed profiles shown in Figure 4 are shown as bold lines; these are labeled: UP, upstream profile; MID, middle profile; DN, downstream profile. Scene size is $77 \mathrm{~km}$ by $71 \mathrm{~km}$. 
across the two tributaries (Fig. 4). The two tributaries of Ice Stream D have markedly different velocities, $\sim 100 \mathrm{~m} \mathrm{a}^{-1}$ for the northern branch, and $\sim 370 \mathrm{~m} \mathrm{a}^{-1}$ for the southern, and more narrow $(\sim 20 \mathrm{~km})$ branch. However, the image shows that both branches have
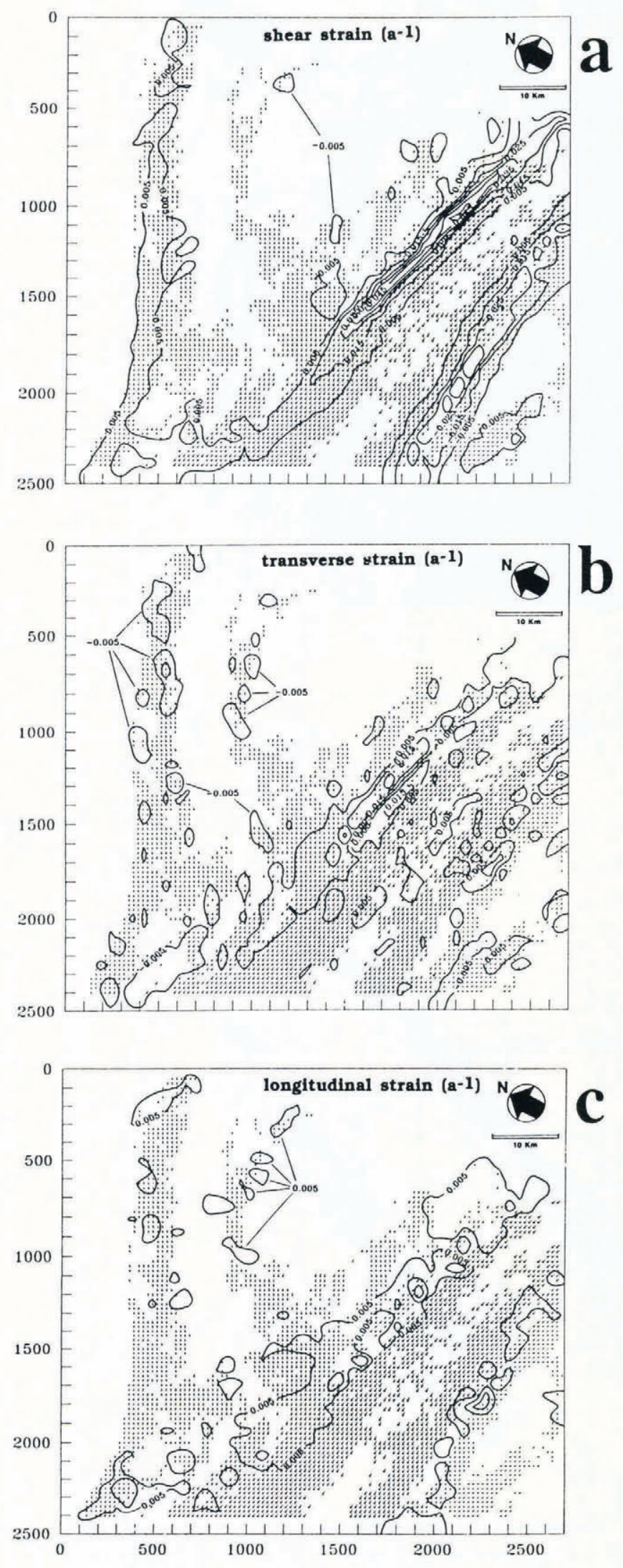

Fig. 3. $a, b$, and c. Strain-rate maps of the study area, showing flowfield arrows as in Figure 2. Contour intervals start at $\pm 0.005 a^{-1}$ and increase by $0.010 a^{-1}$. similar morphological features, such as flow bands, crevasses, and narrow shear margins. Clearly, the presence of flowbands is not a valid indicator of ice speed; ice streams with little difference in surface morphology may be moving at quite different rates. The speed contour map also reveals that narrow ice streams may be moving at quite high speeds. The southern tributary may be compared with the speed and width of Ice Stream E ( $400 \mathrm{~m} \mathrm{a}^{-1}, 75 \mathrm{~km}$ width) and Ice Stream B2 at the Upstream Bravo field camp $\left(\sim 450 \mathrm{~m} \mathrm{a}^{-1}, 35 \mathrm{~km}\right.$ width). All these velocities refer to regions of the ice streams near the $140^{\circ}$ longitude line, areas having roughly similar elevation and slope (Rose, 1979; Shabtaie and others, 1988).

Within the northern tributary there appear to be no sharp "transition zones" from velocities of $<60 \mathrm{~m} \mathrm{a}^{-1}$ to $>120 \mathrm{~m} \mathrm{a}^{-1}$, except for velocity changes associated with the shear margins. Instead, the central portion of the northern tributary shows a gradual increase in speed throughout its length. This suggests that the transition from non-streaming ice to streaming ice can extend over a considerable distance, without much evidence of transverse crevassing (see Fig. 2a). Further, it implies that any changes that may occur in bed characteristics to initiate streaming flow occur gradually, or that the bed is generally compatible with streaming flow, and other factors control its initiation.

Another observation we make from comparing the velocity field map and the imagery is that flowbands in the images are parallel to the ice flow direction throughout the scene. Assuming that flowbands are created at some fixed point with respect to the bed (e.g. Stephenson and Bindschadler, 1990) this implies that flow directions have been stable over a time interval equivalent to the transit time of ice along the flowbands. Individual flowbands in the images may be traced for roughly $30 \mathrm{~km}$ along flow; in the case of the northern tributary, with velocities $\sim 100 \mathrm{~m} \mathrm{a}^{-1}$, the transit time is on the order of 300 years.

The fastest-moving ice, in the center of the southern tributary, is in an area with markedly fewer, smaller topographic undulations. Since topographic undulations are directly related to bed topography, the higher velocity of ice in this area may be due to reduced basal friction because of smaller bed obstructions to flow. This, in turn, may result from a bed that is actually smoother, or from basal fluids causing the ice stream to interact less with bed topography, for example, by surrounding bedrock high spots with thicker layers deformable, water-saturated till (e.g., Alley and Whillans, 1991; Engelhardt and others, 1990). In either case, the observed relationship suggests (but does not prove) that the factor with the strongest control on ice stream speed is bed resistance. However, in regions of higher ice velocity, such as in the southern tributary, or by inference at Ice Stream B2 near the Upstream Bravo field site, shear marginal resistance may be a significant component of the resistive force (e.g., Harrison and Echelmeyer, in press; personal communication from I. Whillans).

Flow speed profiles across the two tributaries illustrate what happens to the two ice streams as they merge (Fig. 4 ). The tributary margins have very steep velocity gradients (although the southern margin of the northern 


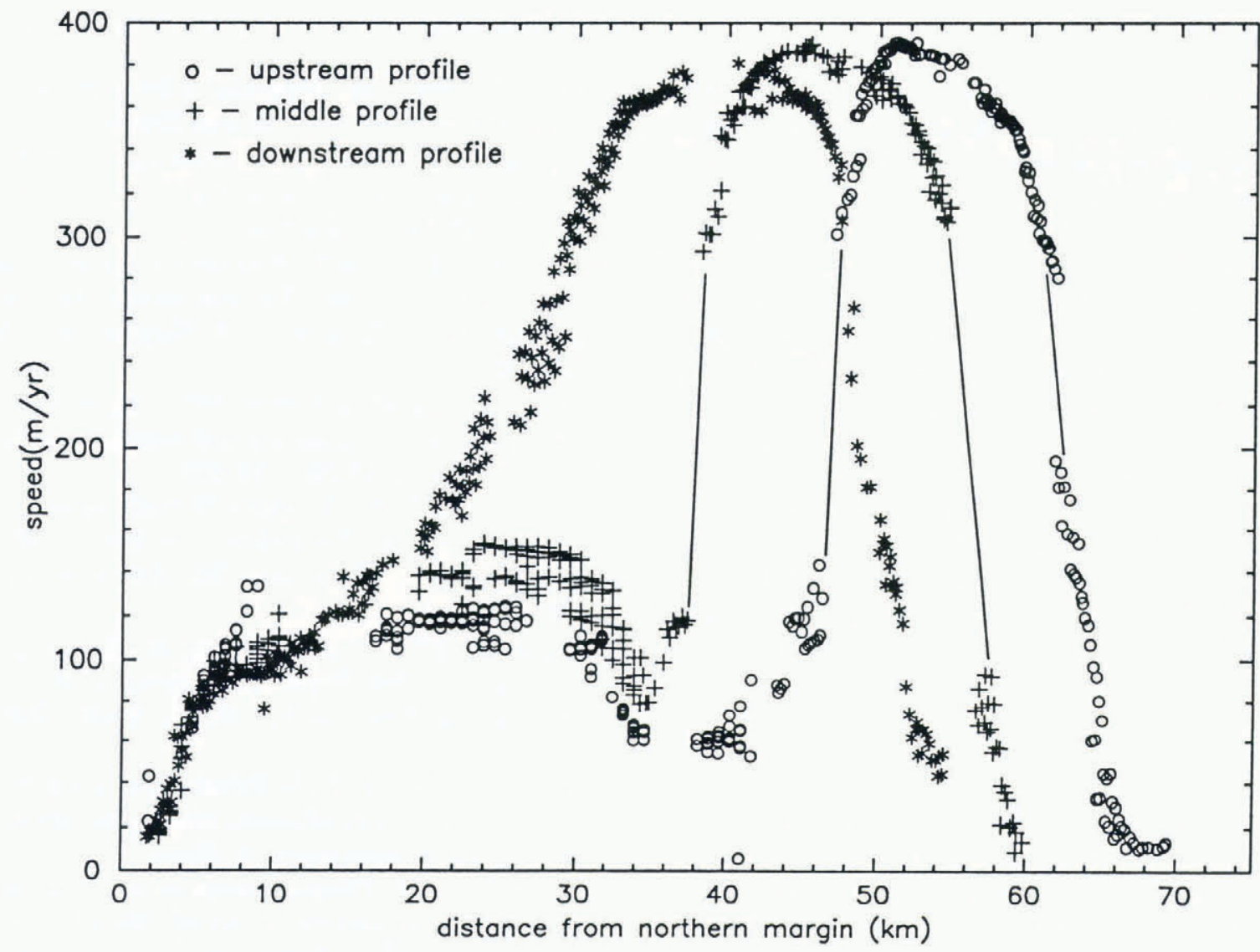

Fig. 4. Speed profiles of Ice Stream D, derived from $2 \mathrm{~km}$-wide swaths of data along the three transects shown in Figure $2 b$.

tributary is less well-defined), and relatively constant velocities in their central portions, typical of velocity profiles observed in other Siple Coast ice streams (Bindschadler and others, 1987; Bindschadler and Scambos, 1991). The tributaries are separated by a narrow region of slower-moving ice (speeds of $\sim 50 \mathrm{~m} \mathrm{a}^{-1}$ ) in the upstream profile, which narrows to a thin septum of slower-moving ice in the middle profile. In the downstream profile, the steep gradient of the faster tributary's margin has disappeared, and instead a broad region of faster-moving ice extends into the slower tributary. The velocity of the faster tributary's midstream area remains essentially unchanged in the three profiles, supporting, again, the hypothesis that the rate of flow is most strongly controlled by shear at the base rather than at the side of the ice stream.

The strain-rate maps reveal several specific areas where the ice is deforming in response to rapid changes in flow direction and speed. These are discussed in the sections below.

\section{Margins of the ice streams}

The most pronounced features of the strain-rate maps, and the location of the highest strain rates, are at the margins of the southern ice tributary. Simple shear dominates the deformation of the margin, with shear strain-rates of up to $0.045 \mathrm{a}^{-1}$ (Fig. 3a). However, these areas also show high negative values of lateral strain-rate and generally positive longitudinal strain-rates, indicat- ing that ice flow from outside the main channel converges and is stretched (in the flow direction) as it becomes incorporated in the faster-moving stream. On the imagery, the margins are characterized by chaotic crevassing and seracs, similar to lateral margins of Ice Stream B and the southern margin of Ice Stream E (Stephenson and Bindschadler, 1990; Vornberger and Whillans, 1986). Simple shear within the ice stream drops off quickly away from the margins, and near the center of the southern tributary the strain-rates are near zero. The northern tributary also shows a high-simple-shear margin on its northern side, although the maximum simple shear strain-rate is much smaller $\left(0.008 \mathrm{a}^{-1}\right)$.

\section{Confluence area of the two main tributaries}

The region where the two main tributaries join is characterized by a large region of convergent flow, high longitudinal strain in the northern tributary, and steadily decreasing shear strain between the two streams as the velocity of the northern tributary increases. Longitudinal strain of the northern arm is greatest where it first comes in contact with the faster ice stream, near line 1500, sample 1300 on Figure 4. The combination of along-flow "stretching" within the northern arm and reduction of shear in the southern arm suggests that the increase in flow velocity of the northern arm is due to response to the drag imparted by the faster arm. As the northern arm accelerates, it narrows, thus roughly conserving its net ice flux (assuming constant thickness). 


\section{Southern area}

South of the southern arm of Ice Stream D the ice shows a complicated pattern of flow. A large wedge-shaped area of the inter-ice-stream ice (near line 2000, sample 2400) is surrounded by low-velocity flow vectors arranged in a "teardrop" pattern. At the upstream end of the flow pattern (line 1600, sample 2600), several flowbands appear to originate. These may be traced around the southern margin of the wedge-shaped area to a region with speeds of $80-100 \mathrm{~m} \mathrm{a}^{-1}$. This area may represent, in miniature, the processes of initiation of streaming flow and acceleration to ice stream velocities. This interpretation is tentative because the area extends south and west of the study area. The small tributary of streaming ice merges into the faster large tributary with the same strain-rate field features as the larger, northern tributary; high longitudinal strain-rates in the slower stream, convergent flow, and reduction of shear strain-rate.

\section{SUMMARY}

Complex flow regions of ice streams may now be studied via sequential satellite imagery through the application of image-matching cross-correlation algorithms to appropriately pre-processed digital images. Collection of velocity and strain-rate data by this method is highly cost-effective relative to field determinations, and at the same time complimentary to field work, which must focus on less dynamic areas, having few image features, for safety reasons. The significance of the new remotely-based method is illustrated by the fact that, although no one has visited this area of Ice Stream D, its regional velocity field is now well-determined. Field studies in this area in the future will be able to better select areas of greatest interest, and the greater detail they provide will be easily extended to areas that are not visited, but are covered by the imagery.

\section{ACKNOWLEDGEMENTS}

We thank two anonymous reviewers for their helpful comments. This work was supported under NSF Grant \#DPP-9018127.

\section{REFERENGES}

Alley, R. B. and I. M. Whillans. 1991. Changes in the West Antarctic ice sheet. Science, 254(5034), 959-963.

Bindschadler, R.A. and T.A. Scambos. 1991. Satelliteimage-derived velocity field of an Antarctic ice stream. Science, 252(5003), 242-246.

Bindschadler, R.A., S. N. Stephenson, D. R. MacAyeal and S. Shabtaie. 1987. Ice dynamics at the mouth of Ice Stream B, Antarctica. 7. Geophys. Res., 92(B9), 8885-8894.

Budd, W.F. and D. B. Carter. 1971. An analysis of the relation between the surface and bedrock profiles of ice caps. F. Glaciol., 10(59), 197-209.

Crippen, R.E. 1989. A simple filtering routine for the cosmetic removal of scan-line noise from Landsat TM P-tape imagery. Photogramm. Eng. Remote Sensing, 55(3), 327-331.

Engelhardt, H., N. Humphrey, B. Kamb and M. Fahnestock. 1990. Physical conditions at the base of a fast moving Antarctic ice stream. Science, 248(4951), 57-59.

Harrison, W. D. and K. A. Echelmeyer. In press. Short period observations of speed, strain, and seismicity on Ice Stream B, Antarctica. 7. Glaciol.

Rose, K.E. 1979. Characteristics of ice flow in Marie Byrd Land, Antarctica. 7. Glaciol., 24(90), 63-75.

Scambos, T. A., M.J. Dutkiewicz, J. C. Wilson and R. A. Bindschadler. In press. Application of image crosscorrelation to the measurement of glacier velocity using satellite image data. Remote Sensing Environ.

Shabtaie, S., C. R. Bentley, R. A. Bindschadler and D. R. McAyeal. 1988. Mass-balance studies of ice streams A, $\mathrm{B}$, and $\mathrm{C}$, West Antarctica, and possible surging behavior of Ice Stream B. Ann. Glaciol., 11, 137-149.

Stephenson, S. N. and R. A. Bindschadler. 1990. Is icestream evolution revealed by satellite imagery? Ann. Glaciol., 14, 273-277.

Vornberger, P.L. and I. M. Whillans. 1986. Surface features of Ice Stream B, Marie Byrd Land, West Antarctica. Ann. Glaciol., 8, 168-170.

The accuracy of references in the text and in this list is the responsibility of the authors, to whom queries should be addressed. 